\title{
The Synthesis of Ammonia from Its Elements-II*
}

\author{
The Commercial Exploitation of the Earth's Atmosphere
}

By Prof. H. A. Bernthsen

Concluded from Scientific American Supplement No. 1929, page 387, December 21, 1912

To sum u p all these investigations on the direct combination of nitrogen and ammonia, it can be said that the problem seemed now to have become more than ever a mere dream, of which the realization appeared to be quite beyond the bounds of possibility, so that there was every reason why the scientist should turn his back on so unfruitful a field.

In spite of this, Haber had a feeling that a technical synthesis of ammonia from its elements could be rendered possible, and placed himself in communication with the Badische Anilin- \& Soda-Fabrik for the promotion of the work. He then showed, still in 1908,11 that the technical preparation of ammonia from its elements can in fact be carried out, in spite of the unfavorable equilibrium and the low catalytic capacity of the contact metals used, if the mixture of nitrogen and hydrogen is kept. under constant pressure during the whole of the operation and is subjected alternately to the catalytic formation of ammonia at a high temperature and then freed from ammonia by absorption or condensation at a lower temperature. Care must at the same time be taken that the heat of the reaction gases containing ammonia is transferred afresh to the gas mixture about to be acted on. In other words, the nitrogen-hydrogen mixture circulates under continuous pressure, through the vessel for the formation of the ammonia, the vessel for the separation of the ammonia and a circulating pump, all these being connected up to a closed endless circuit. Of course it is advisable at the same time to replace with a fresh nitrogen-hydrogen mixture as much replace with a fresh nitrogen-hydrogen
of the gas as is converted into ammonia.

of the gas as is converted into ammonia.
It was further found when working according to this continuous process of Haber's under conditions which induce a relatively high concentration of ammonia that the advantages of the heat regeneration are no longer of such vital importance, bpt that it is, sufficiont in this case to work continuously under pressure without at the same time regenerating heat.12 Finally, it was seen ${ }^{23}$ that it is time regenerating heat. ${ }^{12}$ Finally, it was seen ${ }^{13}$ that it is
not even absolutely necessary to work continuously under pressure (that is, to circulate the gases continuously under pressure), if the reaction is carried out under very high pressure, for instance at about 100 atmospheres, preferably however at from 150 to 250 atmospheres and even higher. A range of pressure is hereby introduced which had never been touched in the synthesis of ammonia and was also something quite new in thesis of ammonia and was also something quite new in
any manufacture, for no ane had previously so much as any manufacture, for no one had previously so much as with gas currents at the necessary high temperature under such an enormous pressure.

By these means, under a pressure of 200 atmospheres, at a temperature of from 650 to 700 deg. Cent. and using an iron catalyst prepared from the purest iron oxid, occupying a space of 20 cubic centimeters, and with a gas speed of 250 liters per hour (measured at ondinny pres sure), it is an easy matter to obtain for example 5 grammes, or per liter of contact space, 250 grammes of ammonia in an hour.

The following further point cames here into consideration. All previous publications had in viaw vexclusively the determination of the ammonia equikibium, which can be found theoretically most ancunately in a steady volume of gas. If a current of is used, the rate of flow must paturally be kept low, so that one may be sure that equilibrium is reached. Now, there no indications as to how far the concentretion of the gas would be reduoed when the rate of flow is raised, and whether the concentration would be sufficient when : whether the flow is taken as must be done when warking on a technical saale. Haber has therefore rendered oignal service cal soale. Haber has therefore rendered dignal service
in showing that one can work sucoesfatly wath such higher rates of flow.

Theoperatus used by Halor ${ }^{14}$ moshiofly described as follows: The catalyst is in a motel tube which opens in tront into a beat regenerator. Thesessmixture passes from behiad into the metal tube, chroush the catalyst and then frough the heat regenerotorinto circulating and then frough the heat regeneratorinto circulating
pump. Lowing this it passes in pump. Le ving this it passes in
the ourtside of the regenerator tutes and the tube contaising the cetalyst and then enters this in trent, repeat-

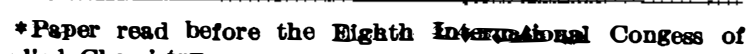
Applied Chemistry.

German Patent No. 235,421, Bctober 13th, 1008.

12 French Patent No. 406,8«3.

'3 German Patent No. 238,450, September 14th, 1909.

14 See the stetches in Haber's article in the Zeit. für Elek-
trochemie, 16, 244-5 (1910) trochemie, 16, 244-5 (1910); ' and also British Patent No.
17,951, 1909. ing this journey again as described. The apparatus can be protected against loss of heat to the air by packing it in isolating material and can be inclosed in an outer shell which ean withstand the presspre. The whole of the circulation takes place at high pressure. The catalys is kept at the suitable temperature by electrically heat ing from within or by applying heat from the outside Between the heat regenerator and the circulating pump the gases pass through either an absorber or a condense for ammonia. By means of a branch tube the nitroge and hydrogen combined to ammonia can be replaced.

Finally, it was a great step forward when Haber found catalysts with the property of rapidly combining nitrogen and hydrogen to ammonia in sufficient quantity even at much lower temperatures than those previously required. He found this to be especially the case with osmium. This metal has such a very favorable action even at $550 \mathrm{deg}$. Cent., and below, that under a pressure of 175 atmospheres a gas concentration of 8 volumes per cent of ammonia can be obtained. This was all the more astonishing, as platinum, which is closely related to osmium, has but a very slight catalytic action. For us on a large scale, however, osmium scarcely comes int consideration, for the world's stock according to Habe does not amount to much over 100 kilogrammes and only small quantities (about 1 killogramme) are obtained annually; this quite apart from its high price and very unpleasant properties.

Very soon Haber found in uranium a further very good catalyst; it ean be employed in the form of the metal, of an alloy, or nitrid, or carbid. In the form containing carbon or carbid, such as is produced in the electric are from uranium oxid and carbon, it crumbles in the gas mixture under high pressure to a very fine powder containing nitrogen, which even under $500 \mathrm{deg}$. Cent. has an excellent catalytic ection. No water, however, or impurities whick give riee to water must be present in the gases, when uranium is used in this way. From the following table which shows the equilibria obtainsble a different temperatures and pressures, be the importance of the temperature at which a eatalyst is active for the equilibrium of the ammon

\begin{tabular}{|c|c|c|c|}
\hline \multirow[b]{2}{*}{$\begin{array}{l}\text { Temp. } \\
\text { Deg. Cent. }\end{array}$} & \multicolumn{3}{|c|}{ Pressure. } \\
\hline & $\begin{array}{l}\text { Atmosphere. } \\
\text { Per Cent. }\end{array}$ & 100 & $\begin{array}{l}\text { Atmospheres. } \\
\text { Per Cent. }\end{array}$ \\
\hline 800 & 0.011 & & 1.1 \\
\hline 700 & 0.021 & & 2.1 \\
\hline 600 & 0.048 & & 4.5 \\
\hline 500 & 0.13 & & 10.8 \\
\hline 400 & 0.48 & & \\
\hline
\end{tabular}

Haber publisher a short report of bis. Whertin 1910. To my great regret Prof. Haber has not beon ablo to report personally here on his researches, owing to being report personally here on his researches, owing to being
hindered by pressure of work. I have great pleasure in fulfilling his wish and thanking the officers of the Congress to-day for the honorable invitation, and express his regret to this meeting that he is unable to be present I now turn to the work of the Badische Anitin- \& Soda-Fabrik on the teehincal development of the process This work was of course at once taken up in 1908 after the first. communications of Prof. Haber, and Dr. Car Bosch was intrusted with it. In conjunction with his colleagues and "with equal energy and experience in th field of chemistry and engineering he has successfully carried out the practical application of the process.

The problems to be solved were quite new and strange and demanded the mastery of very unusual difficulties Although working with compressed gases under pressur Although working with compressed gases under pressur industry, the problem here was the totally different on of constructing apparatus which should be large enoug and at the same time able to witbstand the high pressure with temperatures not far from a red heat. How well founded were the doubts as to the pressibility of a solution of this task can be gathered from the instance of the wrought iron autoclaves commonly used in the celo industry. Here, in spite of a very low range of tempera ture of at most about $280 \mathrm{deg}$. Cent., only presures of from 50 to 100 atmospheres at the utmost cone into consideration. But above 400 deg. Cent. iron 1 ses it solidity to a very extraordinary degree.

There is further the circumstance that the metals which ceme into consideration for the construction of the apparatus; and especially iron, are chemically 1s Zeit. fuir Elektrochemie, 16, 244-5. attacked above certain temperatures by the gas mixture under pressure. Although the formation of iron nitrid from iron and ammonia, which could have been expected according to the work of Fremy and others, can be avoided, yet it is found, for example, that steel containing carbon loses its carbon at the temperatures in question owing to the action of the hydrogen, so that its capability of withstanding pressure is reduced to a minimum. It was further found, when using iron itself, that it is completely changed in its qualities, chiefly by taking up hydrogen. Again, at such high temperatures iron is pervious to quite a remarkable degree to hydrogen under high pressures. The question of materials for the appara tus thereiore raised at once considerable difficulties, but at length these were more than overcome by suitable construction. The danger of serious explosions or of great sudden flames of hydrogen, if the apparatus happens to become defective, can be guarded against by setting it up in bomb-proof chambers.

Great care must naturally be taken that oxygen or air does not get into the apparatus or the piping, for at the high pressure obtaining the explosion range is reached with merely a slight percentage of oxygen. Special devices are used to watch over this content of oxygen, and immediately a definite percentage is touched the alarm is automatically raised. Besides this the proper constitution of the gas mixture in circulation is controlled by analysis from time to time.

The ammonia can be removed either by being drawn directly from the apparatus in liquid form, or an absorption agent can be suitably introduced into the apparatus. The simplest absorbent, water, has been found to be suited for this purpose; under the pressure used a concentrated solution of ammonia is eecured. Any ammonia that may remain in the gas after the bulk has been removed by one or other of these methods can be further removed by special chemical means, if it is not preferred simply to leave it in the ciroulating gases.

As hofore mentioned, Haber observed that there are contact gents which are much more active than those previously known (osmium and uranium being indeed found to be much more active than pure iron prepared from aralate of iron or oxid of iron, platinum, pure mangarese, chromium, and nickel, already at considerably lower temperatures). The Badische Anilin- \& SodaFabrik therefore decided to study the various catalysts ver. minutely.

In the course of these investigations, the new fact discovered, that ammonia catalysts in general are made more active by the presence of certain forrign bodies, hes proved to be of prime importance. Among these "pnamotars," as they have been termed, are oxids, hydroxids, or salts of the allealies, of the alkaline earths and the earth metals, further many other substances of the most varied nature, especially other metal compounds or metals themselves. In many cases just a minute quantity suffices to raise the catalytic activity. This trait is common to all catalysts, for there is not one but its activity can be raised by these means. Care must, however, be taken (for ressons to be discussed later on) not to choose such mirtures that metalloids such as sulphur, selenium tellurium, phosphorus, arsenic, boron, etc., under the conditions prevailing, are incorporated in the catalyst. Similarly compounds of metals with a low melting point which are readily reduced by hydrogen and which themselves do not a $t$-as eatalysts must be avoided; such motals themselves as lead, tin, zinc and bismuth must also, not be added.

The promoters mentioned can be added either to the prepared catalyst or to the substances used in its preparation, or the catalyst can be prepared from su h materials as. already contain such additions in suitsble mixture (for example magnetic ironstone). Under certsin circumstances the action of these foreign bodies is specially powerf ul, viz., if the metals, or oxids, or carbonates, or other , vic., in wich are convented into oxids on heating, are hitit heated to high temperatures, preferably to melfing point, and so that the resaltiog product cansissts chiefly of oxids. When proceding in this way with metals, for instance iron, of course sufficient oxygen or oxygen-producing c mp unds must have 200ess. The mass of oxids obtained as described is suitably broken up and filled into the contact stove either directly or after reduction. In this case extremely small quantition of foreign subtances suffice to secure a high and continuous activity of the contact mass.

We consider the marked activity of catalysts prepared in this way to be in the first place due to the fact that 
the additions mentioned dissolve, on heating, in the highly heated metallic oxid or become finely divided in it, and that in this way during the following reduction a sort of skeleton, which however is hardly to be detected, is formed inside the metallic mass. This effectually prevents a diminution of the surface and therefore als of the catalytic properties of the mass.

It was then further found that good results can also be achieved with pure iron, that is to say, that we can work with it at temperatures of for example not much above $600 \mathrm{deg}$. Cent., thus if the iron intended for the catalysis is prepared from the oxid or other iron compound at a comparatively low temperature, preferably not above $600 \mathrm{deg}$. Cent. It can also be prepared by highly heating pure iron oxids, or pure iron in the presence of oxygen, preferably to melting point, and by reducing the mass of oxid preferably at a not too high temperature.

Also manganese, which is related to iron, gives under a specific condition good results, without the addition of foreign substances. This condition is that care be taken to free completely the mixture of nitrogen and hydrogen before it enters the contact space, from oxygen, eithe free or combined, for instance as steam or water. Merely drying with calcium ehlorid is not suffecient. In the case of several other catalysts too a similar careful dryin has proved to be useful.

Again it has been found that another member of the iron group, molybdenum, is by itself an excellent cata lyst. Compounds of molybdenum ean also be used, fo instance molybdic acid or ammonium molybdate.

Under certain conditions, not published as yet, tungsten, either the metal itself or as an alloy or a nitroge compound, has been found to be a suitable catalyst.16

In view of the shortness of the time I must refrain from a more exhaustive discussion of this most interesting chapter of the contact bodies. It will be quite evident from what $I$ have said that the industry has now a number of active contact bodies for the synthesis of ammonia at its disposal, and can select from case to case the most suitable.

Another discovery of first-class importance for the industrial application of the catalysis of ammonia was the recognition of the fact that there are special poisons, so to speak, for the reaction. That is to say, there are substances which hinder or prevent the reaction, althoug the contact mass does not suffer a noticeable chemical change, envelopment, or destruction. In the literature there was no indication whether there were poisons at all for the contact mass in the catalytic manufacture of ammonia, or what their nature would be. In actual manufacture such contact poisons were known only in the case of the catalysis of sulphuric anhydrid and even here only when platinum was used. When employin other contact bodies, such as iron oxid, or burnt pyrites, there was nothing known of contact poisons; on the contrary, it has even been shown that the presence of arsenic, which is a poison for platinum, has actually favorable action when iron oxid is used as catalyst.

It has now been ascertained that some of the poisons in the syntheses of ammonia are of quite a different nature from those of the sulphuric acid process; they are for instance, sulphur, selenium, tellurium, phosphorus, arsenic, boron, or the compounds of these elements such as sulphuretted hydrogen, arsenic hydrid, phosphorus hydrid, as also many carbon compounds and certai metals of low melting point which can readily be reduced by hydrogen from their compounds, for example lead, bismuth and tin, whicb do not act oatalytically. Oxygensulphur compounds, such as $\mathrm{SO}_{2}$, which acts directly and smoothly in the sulphuric acid catalysis, are very poisonous. Extremely minute quantities of these bodies which are almost always present even in the purest commerical products or in the so-called pure gases, suffics to render the catalysts absolutely inactive or at least to diminish their action very seriously. Thus iron, for example, prepared from ordinary iron oxid with a content of one per thousand of sodium sulphate is, as a rule inactive. Iron containing one tenth per cent of sulphur is generally quite useless, and even with one hundredth per cent is of very little use, although in appearance and when examined with the ordinary physical and chemical methods no difference at all can be detected as compared with pure iron.

The recognition of these facts gave rise to two prob-

(a) The preparation of contact masses free from poison or the removal of such poisons from them.

(b) Freeing the gases to be acted on catalytically from all contact poisons.

In order to free the contact bodies from these harmf u substances, the ordinary methods for removing them ea of course be applied. The contact action can also be improved by heating contact metals which are inactive

${ }^{16}$ Such conditions are, e. $\mathrm{g}$, that tungsten, or its com pounds mentioned, is prepared at temperatures not much above 600 deg. Cent, that they are prepared from tungste
compounds by means of ammonia, in which case there is restriction to a temperature at about 600 deg. Cent. or of little use, owing to the presence of contact poisons, in the presence of oxygen or of bodies yielding oxygen. Or the metals can be heated, for instance, in the presence of oxygen with the addition of suitable compounds such as bases, and the resulting products reduced. These operations can be repeated if necessary. If more of such a body as mentioned is added than is necessary, it may act not merely by removing the poisons, but promote the yield, as I have already described to you.

On the other hand it is necessary, as I remarked, to take the greatest care that nitrogen and hydrogen are free or freed completely from all contact poisons. Thus a trace of sulphur, one part per million, in the gas mixure can under certain conditions be injurious, so that even electrolytically prepared hydrogen must generally be further purified. The minute purification of the gases is even more important when hydrogen prepared, for example, from water gas is used. The impurities, too, taken up from iron piping play sometimes an important part, and impurities which get into the gases during the compression, such as machine oil, of ten have a harmful effect.

The best method of removing impurities from the gas mixture depends in turn on the nature of these imptrities and consists, for instance, according to the case, in filtering, washing, conducting over solid absorption agents and so on. One good method is to bring the gases into contact with the material of which the contact mass is prepared at a raised temperature, before passing them over the actual catalyst. The material takes up the impurities, and must of course be renewed from time to time. The negative results of earlier investigators in the formation of ammonia when using base contact metals (Wright, Ramsay and Young, and, more recently again, 1911, Neogi and Adhicary), according to which nitrogen and hydrogen do not combine in the presence ot iron, are in my opinion probably due, for the most part at least, to the use of metals or gases not free from contact poison. That previous inquirers had not the remotest idea that sulphur in the contact metal could be injurious, is evident from the fact that they passed the gases without hesitation through concentrated sulphuric acid in order to dry them. The sulphuric acid thus taken up and the sulphur dioxid of ten contained in it can poison even the best catalyst very speedily and render it unfit for use. Or the contact metals were sometimes prepared directly from the sulphates, although a metal sufficiently free from sulphur can scarcely be obtained by this method.

A painstaking study, for which we are indebted principally to Dr. A. Mittasch and which involved literally many thousands of experiments, has afforded an insight into the importance of substances of the most varied nature as promoters and poisons and thus a sure foundation has been prepared for a reliable continuous manuacture with a good yield of ammonia.

The question has not yet been touched upon in the foregoing, how the elements, nitrogen and hydrogen, which are requisite for the new ammonia process, can best be produced on a technical seale. Theoretically, the task would be unusually simple. If you remember that the terrestrial atmosphere according to the studies of A. Wegener and others consists of practically pure hydrogen at a height of about 120 kilometers, indeed at a height of about 70 kilometers consists of almost exactly one volume of nitrogen and three volumes of hydrogen besides a trace (about one half per cent) of oxygen, you will understand that all the conditions were given for an ammonia factory according to Jules Verne. For it would then merely be necessary to suck down the gases from the higher strata of the atmosphere by a sufficiently long pipe line.

For us, poor mortals, matters are not so ideally simple, for, as the poet siys,

"hart im Raume stossen sich die Sachen."

Fortunately, however, there is no great difficulty in separating nitrogen from the air, either by physical means, according to Linde's process, or chemically, by removing the oxygen with glowing copper, buming hydrogen, or the like. And for the preparation of hydrogen in recent times a great deal of useful work has been done too, owing to the extensive growth of its field of application. In certain works it.is at disposal in lange quantities as a by-product of the electrolysis of common salt. Besides this it can be produced, for example, by passing steam over red-hot iron, or from water-gas, for instance, by separating its constituents hydrogen and carbon monoxid by cooling to a very low temperature. All the methods of preparation which come into eonsideration we have of course minutely examined; owing to the comparatively trifling differences in the cost of production various methods can be employed. At all events, both elements, nitrogen and hydrogen, are at the disposal of the new industry to any extent and sufficiently cheap. As the production of these elements is not confined to the presence of cheap water power, all those countries where the manufacture of calcium nitrate, owing to the want of such power, is not practicable, as for instance in Germany, are now in a position to profit by the new in-
CHILI SALTPETER.

\begin{tabular}{|c|c|c|c|c|}
\hline Ye & $\begin{array}{l}\text { Chilian } \\
\text { Export.1 }\end{array}$ & $\begin{array}{l}\text { Prices } \\
\text { per Ton. } \\
\text { Marks. }\end{array}$ & $\begin{array}{l}\text { Total } \\
\text { Volue } \\
\text { Mill M. }\end{array}$ & Increase. \\
\hline 300 & $1,454,000$ & 162.2 & 216.6 & $1901-11995,400$ tons \\
\hline 190 & $1,274,000$ & 172.8 & & is an annual \\
\hline 190 & $1,379,200$ & 176.2 & & 99,500 \\
\hline 03 & $1,457,600$ & 178.4 & & tons containing 15.5 \\
\hline 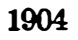 & $1,479,100$ & 196.2 & & per cent, i. e., about \\
\hline 05 & $1,652,200$ & 204.8 & 338.2 & 15,400 tons nitrogen, \\
\hline 06 & $1,731,800$ & 215.0 & & valued at 19 million \\
\hline 07 & $1,653,600$ & 214.4 & & marke. \\
\hline
\end{tabular}

$1907 \quad 1,653,600 \quad 214.4$

$1908 \quad 2,052,400 \quad 193.3$

$\begin{array}{lllll} & 2,133,900 & 184.5 & 393.7 & \text { First six months } 1912\end{array}$ $\begin{array}{lllll}1910 & 2,334,000 & 177.6 & . . & 150,000 \text { tons valued }\end{array}$

Jan.-June

$1911\left(1,299,000^{3}\right)$

$19112,449,000$

$190.7 \quad 46 \ddot{67.2}$ at about 29 million marks as a g a in s 1911 .

$912\left(1,449,000^{3}\right)$

According to the figures of the Association Salitrera.

Semi-annual deliveries in quotation

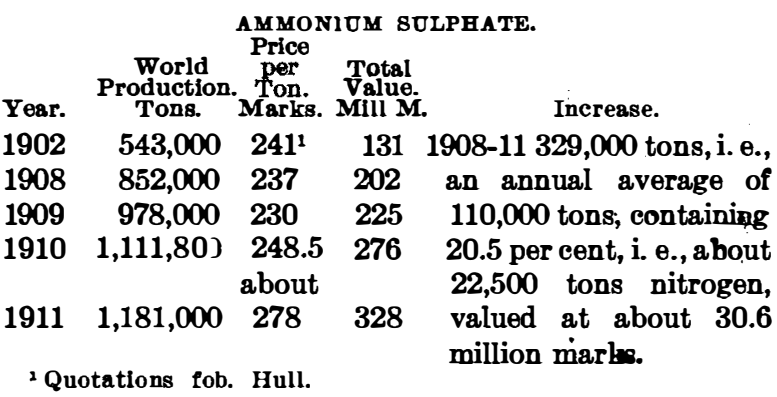

dustry. As I remarked at the outset, there is every reason to assume that this industry will find a fruitful
field of employment in America, where the demand for nitrogen manures will soon be greater than hitherto.

It can also be regarded as certain that the developof other branches of industry and commerce. Bear in mind for a moment the present annual requirement for nitrogen manures and their continued growth. According to the tables these figures reached the remarkable total of $467.2+326$, i. e., 793.2 million marke (about 189 million dollars) in 1911, and each year sees an increase. . In the last few years the inereased demand for ammonium sulphate amounted to about 10 per cent. The increase of production from 1910 to 1911 amounted to 69,000 tons, and from 1908 to 1911 on the average as much as 110,000 tons, or 110 million kilogrammes valued at about 30.6 million marks (7.3 million dollars). Similarly the nitrogen requirements of the world for manur purposes in the form of saltpeter is growing, Chili already in 1911 the figure was about $2,449,400$ tons, that is an annual increase of nearly 150,000 tons valued at approximately 29 million marks $(\$ 7,000,000)$. Indeed the European deliveries, accurding to the latest reports, from January to the end of June, 1912, reached as much as $1,449,000$ tons, a demand which Chili was hardly able to meet.17 The average annual increase from 1901 to 1911 amounted to 99,500 tons. That is to say, taking saltpeter and ammonium sulphate together and reckoning only the average increases, calculated on nitrogen, re have an annual increase in production of about 38,000 tons nitrogen, corresponding to nearly 185,000 tons of ammonium sulphate.

It can thus be seen that enormous quantities of synthetic ammonium sulphate must be produced to affect the total production by as much as one year. The saying 80 of ten applicable, that

"Das Bessere ist der Feind des Guten," 18

will thus probably have no meaning in this field. A peaceful development of the various new industries for the combination of the nitrogen of the air side by side is to be expected, and without encroaching at all on the previous production of nitrogenous manures, a favorable horoseope may be cast for a fortunate career for the new industry.

\section{Antifreezing Solutions}

A prominent motor truck company has sent out the following antifreezing formulæ to its customers:

Thirty to 15 degrees above zero: Wood alcohol, 10 per cent; glycerin, 10 per cent; water, 80 per cent.

Fifteen to 8 degrees above zero: Wood alcohol, 121/2 per cent; glycerin, 121/2 per cent; water, 75 per cent. Eight degree above to 10 degrees below zero;
Wood alcohol, 25 per cent; glycerin, 12 per cent; water, 63 per cent.

Ten to 20 degrees below zero: Wood alcohol, 50 per cent; glycerin, 25 per cent; water, 25 per cent.

${ }^{17}$ During the first six months of 1912 the production in Chill was roughly 10,000 tons less than in the corresponding that country receded by round 50,000 tons. 18 Freely translated this might be rendered: "The only
menace to a good thing is a better." 